\title{
Sexual Trauma, Substance Abuse, and Treatment Success in a Sample of African American Women Who Smoke Crack Cocaine
}

\author{
Amy M. Young, Ph.D., ${ }^{1}$ and Carol Boyd, Ph.D., R.N., FAAN ${ }^{2}$
}

The purpose of this descriptive study was to examine the relationship among sexual trauma, severity of substance use, and treatment success for African American women who smoke crack cocaine. Using a convenience sample of 208 African American women with a history of crack smoking, participants were interviewed for 2 to $4 \mathrm{hr}$ and asked a variety of questions about their health, relationships, sexuality, and drug use. Women with a history of sexual trauma $(\mathrm{N}=134)$ reported being addicted to more substances than women who had not been sexually traumatized $(\mathrm{N}=74)$, despite the fact that the two groups did not differ on the number of substances used. Differences in the self-reported level of substance abuse was corroborated with external evidence of group differences in substance abuse severity. Women with a history of sexual trauma, compared to women without such a history, were admitted to the hospital or emergency room more often for health issues related to their substance use and were more likely to be negligent in caring for their children because of their drug use. We also found evidence to suggest that there are differences in treatment success between the two groups; women with a history of sexual trauma reported having been to substance abuse treatment programs more often than women without such a history. These findings are discussed in light of the particular treatment needs of women with a history of sexual trauma.

KEY WORDS: sexual trauma; crack cocaine; women.

\section{INTRODUCTION}

Crack cocaine use among women, particularly African American women, has been growing at an epidemic rate over the past two decades. Crack cocaine use can have profound effects on the lives of its users; more than with other illegal drugs, crack cocaine use has the potential to jeopardize one's personal safety, health,

${ }^{1}$ Substance Abuse Research Center, University of Michigan, 475 Market Place, Suite D, Ann Arbor, Michigan 48109-1649.

${ }^{2}$ Substance Abuse Research Center and Nursing/Women's Studies, 475 Market Place, Suite D, University of Michigan, Ann Arbor, Michigan 48109-1649. 
relationships, and employment. Furthermore, the use of crack cocaine appears to be linked indirectly to the spread of HIV because of the promiscuous sex that is endemic to crack-using subcultures (1). Not surprisingly, the incidence of HIV among African American women has increased in conjunction with the increase of crack use among this population (2) and African American women currently comprise the majority of women with HIV (3).

Despite the ramifications of crack cocaine use, little is known about why African American women use this substance. The field of substance abuse has often been criticized for its lack of attention to issues pertaining to African American women's substance use (4) and their crack cocaine use in particular (5). The purpose of this investigation is to fill the void in the literature by examining how previous experiences of sexual trauma are related to the severity of addiction and lack of success in substance abuse treatment among a population of African American crack cocaine users.

\section{Background}

Previous experiences of sexual trauma appear to be prevalent among women who use crack cocaine. Paone and colleagues, in one of the few studies to examine crack cocaine use and previous experiences of sexual trauma, found that a history of sexual abuse was common in their sample of 146 indigent women who had a history of crack cocaine abuse (6). Approximately one-half of the sample (51\%) reported having been victims of at least one forced sexual encounter. Likewise, Wallace found high rates of sexual trauma among other forms of trauma, which occurred prior to the onset of addiction, among 245 adults in treatment for crack cocaine (7).

Although there are few studies that report the incidence of sexual trauma among users of crack cocaine, the high incidence of sexual trauma among women who abuse other licit and illicit drugs has been well documented. Across a wide spectrum of substances and populations, researchers consistently find a high rate of sexually traumatic experiences among substance abusing women, including women in chemical dependency treatment programs $(8,9)$, women in alcohol treatment programs (10), chemically dependent women in the criminal justice system (11), undergraduate women with alcohol and drug problems (12), and women with a history of eating disorders (13).

Despite the fact that previous experiences of sexual abuse are prevalent among female substance abusers including female crack cocaine users, the few studies that actually have examined the relationship between sexual abuse and crack cocaine per se are inconsistent. Paone and colleagues found that sexual abuse was related to behaviors that presented a high risk for substance abuse, such as initiation for drug use by age 15 , pressure by a male partner to use drugs during pregnancy, and engaging in sex for drug transactions (18). In contrast, El-Bassel and colleagues failed to find an association between the use of crack cocaine and previous traumatic experiences, including sexual trauma, in a sample of 158 incarcerated women with a recent history of drug use (19). After controlling for social support, coping behavior, demographics, and criminal history variables, they found that whether or not a 
woman was using crack cocaine was related to current experiences of trauma (e.g., loss of child), although they noted that these traumas are likely the sequel to crack cocaine use, not the precipitant. In contrast, though, there was no association between crack use and previous experiences of trauma, such as childhood sexual or physical abuse, or parental alcohol abuse.

Inconsistencies in the findings concerning crack cocaine use and previous experiences of sexual trauma may be due to how researchers define and operationalize substance abuse. Of particular importance may be whether sexual trauma is related to the individual's severity of substance use (i.e., degree of addiction), as opposed to the individual's use (or lack) of substances. Women with a history of sexual trauma may be just as likely as women without such a history to use substances; however, they may be more likely to become addicted and less likely to be able to break their addiction. Research on substance abuse treatment outcomes of individuals with PTSD symptoms supports the proposition that the addiction of individuals who have experienced trauma is distinct from the addiction of those without such experiences. Ouimette and colleagues found that substance abusing veterans with PTSD symptoms were more likely to have drug and alcohol abuse problems 1 year following treatment than substance abusing veterans without a psychiatric diagnosis or with a psychiatric diagnosis besides PTSD (20). While the study by Ouimette and colleagues was conducted with male war veterans, whose experiences of trauma may be distinct from those of sexually traumatized females, research on long-term treatment outcomes of women with a history of sexual trauma supports the findings from Ouimette and colleagues' study. Brown found that substance-dependent women who had PTSD symptoms relapsed more quickly than substance-dependent women who did not have these symptoms (21). These research findings support what many clinicians and theorists have previously noted about women's experiences of sexual abuse, addiction, and treatment. Theorists who study trauma and substance abuse note that rapid relapse can almost be expected in sexually traumatized women, if the underlying issues related to the trauma have not been addressed during treatment $(22,23)$. Likewise, substance abuse treatment professionals have often characterized substance abusing women who have a history of sexual trauma as being difficult, resistant to treatment, and unlikely to improve (24). Because women with a history of sexual trauma, in contrast to women without such a history, may use substances as a means of coping with psychological issues related to their trauma, they may be more likely to become addicted and less likely to be able to break their addictions without treatment that addresses the underlying psychological issues related to the traumatic event(s).

\section{Purpose}

Given the absence of research on African American women's experience of sexual trauma and drug use, the purpose of this study was to examine the relationship among sexual trauma, severity of substance use, and treatment success for African American women who smoke crack cocaine. We hypothesized that women with a history of sexual abuse who smoke crack cocaine would be more severely addicted to substances compared to women without such a history who smoke crack cocaine. 
We expected the differences in the severity of addiction between these two groups to be evident in both subjective and objective indicators. First, we predicted that women with a history of sexual abuse would report being addicted to more substances compared to women without such a history. We also expected differences in the severity of addiction to be evident in objective indicators that measured the detrimental effect substance abuse had on the women's lives. Thus, our second prediction was that women with a history of sexual abuse, in contrast to women without such a history, would be more likely to report being admitted to the hospital and emergency room for substance abuse related reasons. Third, we predicted that women with a history of sexual abuse, in contrast to women without such a history, would be more likely to report that substance use interfered with the care of their children.

In addition to differences in the severity of addiction, we also hypothesized that women with a history of sexual trauma would be less successful at breaking their addictions than women without a history of sexual trauma. Thus, our fourth prediction was that women who had been sexually traumatized would have been in drug treatment more times than women who had not been sexually traumatized.

Even though we expected differences in the degree of addiction, we did not expect differences between the two groups on the number of substances used. Our expectation was based on previous research suggesting that crack cocaine abusing women with PTSD symptoms, compared to crack cocaine abusing women without such symptoms, are more likely to become addicted to substances but are not likely to use more substances.

Finally, we wanted to explore which characteristics of sexual trauma were most pertinent to substance abuse. Thus, we also conducted exploratory analyses on the relationship between descriptive information regarding the trauma (i.e., duration of abuse, age at onset, relationship to perpetrator) and variables pertaining to substance abuse (i.e., use of substances, severity of addiction, and treatment success).

\section{METHOD}

\section{Procedure}

This descriptive investigation was a secondary analysis of an existing data set pertaining to women's crack cocaine use (for more information on the existing data set see Refs. 25 and 26). Women were eligible for the study if they were over the age of 18 and had used at least $\$ 100$ worth of crack cocaine per week. Women who were enrolled in one of two treatment programs in a large metropolitan area were asked to be part of the study $(n=152)$. These women were required by the treatment program to remain abstinent from illegal and mood altering drugs while in treatment. A smaller subsample of women who were currently using crack cocaine was also obtained $(n=56)$ through informal contacts within a community that had a significant crack cocaine problem. Women who were currently using crack were contacted in their homes and interviewed at a local library, while women in treatment were interviewed within the treatment facilities. Each interview required 
approximately $3 \mathrm{hr}$ to complete. The questionnaire included standardized measures as well as open-ended questions regarding the women's drug and alcohol use, family and social network, and physical and psychological health. Informed consent was obtained and because women were reporting criminal activities, a Certificate of Confidentiality from the Department of Health and Human Services was obtained by the principal investigator. At the end of the interview each woman received $\$ 20$.

\section{Participants}

This convenience sample consisted of 207 participants who ranged in age from 19 to 48 , with a mean age of $30.3(\mathrm{SD}=5.42)$. Forty-seven percent $(n=96)$ of the women had less than 12 years of education, 33\% $(n=68)$ were high school graduates, and $20 \%(n=41)$ had completed some college (see Table I). Twentyone percent $(n=41)$ were employed either full- or part-time, $47 \%(n=93)$ were unemployed and looking for work, and $28 \%(n=55)$ were unemployed and not looking for work. The sample had low household incomes; 68\% $(n=135)$ reported an income of less than $\$ 10,000$ and only $6.5 \%(n=13)$ reported an income of over $\$ 15,000$. Sixty-three percent $(n=129)$ of the women had never married, $18 \%$ $(n=37)$ were divorced, widowed, or separated, and 19\% $(n=39)$ were either

Table I. Demographic Characteristics of Crack Abusers

\begin{tabular}{|c|c|c|c|}
\hline Characteristic & $\begin{array}{c}\text { Entire } \\
\text { sample } \\
(N=209)\end{array}$ & $\begin{array}{c}\text { History } \\
\text { of sexual } \\
\text { trauma } \\
(N=127)\end{array}$ & $\begin{array}{c}\text { No history } \\
\text { of sexual } \\
\text { trauma } \\
(N=80)\end{array}$ \\
\hline \multicolumn{4}{|l|}{ Education $(\%)$} \\
\hline Less than 12 years & 46.8 & 46.5 & 47.4 \\
\hline High school graduate & 33.2 & 33.0 & 33.4 \\
\hline Some college & 20.0 & 20.5 & 19.2 \\
\hline \multicolumn{4}{|l|}{ Income $(\%)$} \\
\hline 0 to $\$ 2,999$ & 14.6 & 14.9 & 14.1 \\
\hline$\$ 3,000$ to $\$ 4,999$ & 30.6 & 29.7 & 32.1 \\
\hline$\$ 5,000$ to $\$ 9,999$ & 22.6 & 24.0 & 20.5 \\
\hline$\$ 10,000$ to $\$ 14,999$ & 12.6 & 11.6 & 14.1 \\
\hline$\$ 15,000$ to $\$ 49,999$ & 2.5 & 3.3 & 1.3 \\
\hline$\$ 50,000$ and over & 4.0 & 5.8 & 1.2 \\
\hline Refused to report income & 13.1 & 10.7 & 16.7 \\
\hline \multicolumn{4}{|l|}{ Marital status $(\%)$} \\
\hline Never married & 62.9 & 60.3 & 67.1 \\
\hline Divorced, widowed, or separated & 18.1 & 19.9 & 15.2 \\
\hline Married or living as married & 19.0 & 19.8 & 17.7 \\
\hline \multicolumn{4}{|l|}{ Employment (\%) } \\
\hline Employed full- or part-time & 20.8 & 25.6 & 13.2 \\
\hline Unemployed and looking for work & 47.2 & 43.0 & 53.9 \\
\hline Unemployed and not looking & 27.9 & 28.1 & 27.6 \\
\hline \multicolumn{4}{|l|}{ Age (years) $(\%)$} \\
\hline $19-24$ & 11.2 & 11.9 & 10.0 \\
\hline $25-29$ & 37.8 & 38.1 & 37.5 \\
\hline $30-34$ & 27.2 & 27.8 & 26.3 \\
\hline $35-39$ & 16.5 & 12.7 & 22.5 \\
\hline $40+$ & 7.3 & 9.5 & 3.7 \\
\hline
\end{tabular}


married or living as married. Nearly all of the women had children (93\%, or 192), averaging 3.4 children each $(\mathrm{SD}=2.0$; range, $1-17)$.

Crack cocaine was the drug of choice for all participants in this study; however, many women in the sample previously or currently used a variety of drugs. Within the last 2 years, $70 \%$ reported using alcohol, 51\% reported using marijuana, 20\% reported using cocaine $\mathrm{HCL}$, and $10 \%$ reported using heroin. On average, crack cocaine use began at age 25 years $(\mathrm{SD}=5.43$ years) and ranged from 13 to 42 years of age. The median amount of money spent on crack cocaine was $\$ 200$ per week and the majority of women reported being addicted to crack.

Sixty-two percent $(n=126)$ reported at least one sexually traumatic experience, $20 \%(n=38)$ reported sexual trauma by a stranger (i.e., rape), 12\% $(n=23)$ reported sexual trauma from a known person, $24 \%(n=47)$ reported sexual trauma by a family member (i.e., incest), and 7\% $(n=14)$ reported sexual trauma from a stranger as well as a family member. Most women $(64 \% ; n=125)$ reported more than one episode of sexual trauma. The mean age at the first sexually traumatic experience was 14.4 years. There was considerable variation in the age at first sexual trauma; the age at first trauma was approximately 10 or 11 for women who were victims of incest but was approximately 16 for women who experienced sexual trauma from an unknown or unrelated known person.

\section{Instruments}

Experience of Sexual Trauma. Whether or not the participant had experienced sexual trauma was determined by asking if she had ever had an experience in which someone tried to make her, not necessarily violently, have sexual activity that she did not want. Participants were informed that this could include having been forced to have intercourse or other forms of sexual activity. A dichotomous variable was created that discriminated between "yes" and "no" responses to this item.

Characteristics of Sexual Trauma. If the women indicated that they had been sexually traumatized, they were then asked a series of questions about their experiences, such as the number of times the trauma had occurred, their relationship with the perpetrator, and their age when the abuse began and when it ended. A difference score between when the abuse began and when it ended was used to create a variable pertaining to the duration of the abuse.

Severity of Substance Abuse. Substance abuse severity was operationalized with five indicators that included both subjective and objective measures of severity of addiction. The women were asked a series of questions about their drug and alcohol use, both in terms of their substance use in general and in terms of their use of specific substances (i.e., marijuana, amphetamines, sedatives, cocaine HCL, crack cocaine, heroin, opiates, PCP, psychedelics, inhalants, and alcohol). For each of the specific substances, the participants were asked whether they believed that they are or were addicted to the drug. Responses for each of the substances were summed to provide a measure of the number of drugs to which participants were addicted (indicator 1), which was used as a continuous variable in the analyses. For each of the substances, participants were also asked whether they had ever been so high on drugs that they were unable to take care of their children. Responses 
were summed across specific substances to create overall indicators of the extent to which drugs interfered with care for their children and themselves (indicators 2 and 3), which were both used as continuous variables in the analyses. Other measures of severity of substance use were based on the women's use in general. Participants were asked whether they had ever been admitted to an emergency room because of their alcohol or drug use (indicator 4), which was used as a dichotomous variable in the analyses. Finally, they were asked whether they had ever been admitted to a hospital for physical problems related to drug use (indicator 5), which was also used as a dichotomous variable in the analyses.

Substance Abuse Treatment. Participants were asked to indicate the number of times they had been in treatment, which was used as a continuous variable in the statistical analyses.

Age at First Substance Use. Participants were also asked about their first experience with an illegal drug, including how old they were when they had this experience. This item was used as a continuous variable in the analyses.

\section{Data Analysis Strategy}

Data were analyzed using SPSS 9.0. Group comparisons between women who had a history of sexual trauma and those who did not were made with Student $t$ tests and Pearson's chi-square tests. Demographic information was first analyzed to determine if there were group differences in the backgrounds of the two groups. Hypothesis testing was then conducted by determining whether there were group differences for variables concerning the women's drug use and the effects of their drug use. Finally, exploratory analyses were conducted with Student $t$ tests, Pearson's chi-square tests, and Pearson correlation tests to determine whether particular characteristics of sexual trauma (incest, age at onset, duration of abuse, and number of times) were related to each of the variables pertaining to the women's drug use (use of substances, addiction to substances, substances interfering with care of children, drug-related hospital and emergency room visits, and number of times in treatment).

\section{RESULTS}

Our first hypothesis was that women using crack cocaine who had been sexually traumatized would be more severely addicted to substances than women using crack cocaine who had not been sexually traumatized (see Table II). Our predictions based on this expectation were confirmed. The women in our sample who had a history of sexual trauma reported being addicted to more substances than the women who did not have a history of sexual trauma (trauma $=1.48$, no trauma $=$ $1.18 ; t=2.15, p<.05)$. There were also significant differences between the groups in the rates of hospital admissions and emergency rooms visits for substance-related health problems. Whereas $30 \%$ of the women with a history of sexual trauma had been admitted to the hospital for substance-related problems, only $13 \%$ of the women without a history of sexual trauma had been admitted. Likewise, $37 \%$ of 
Table II. Group Differences in Indicators of Severity of Addiction and Treatment Success

\begin{tabular}{ccc}
\hline & \multicolumn{2}{c}{ Mean (SD) } \\
\cline { 2 - 3 } Indicator & $\begin{array}{c}\text { History of } \\
\text { sexual trauma }\end{array}$ & $\begin{array}{c}\text { No history of } \\
\text { sexual trauma }\end{array}$ \\
\hline Number of substances addicted to in past 2 years* & $1.48(0.96)$ & $1.18(0.96)$ \\
$N$ & 125 & 77 \\
Number of substances used in past 2 years & $2.76(0.98)$ & $2.61(1.08)$ \\
$N$ & 127 & 78 \\
Number of substances used that have interfered & $0.84(0.88)$ & $0.59(0.65)$ \\
with care of children* $N$ & 127 & 78 \\
Number of times previously in treatment** & $2.39(2.19)$ & $1.48(0.93)$ \\
$N$ & 77 & 40 \\
\hline
\end{tabular}

Note. ${ }^{*} p<.05 ; * * p<.01$.

the women with a history of sexual trauma had been admitted to the emergency room for substance-related problems, while only $20 \%$ of the women without a history of sexual trauma had been admitted. There were also differences between the groups on the extent to which substance use interfered with the care of their children. Women who had a history of sexual trauma reported that more substances interfered with the care of their children than women who did not have a history of trauma (trauma $=.84$, no trauma $=.59 ; t=2.36, p<.05$ ). In contrast, there were no significant differences between the two groups on the number of substances used.

We also expected there to be differences between the groups in treatment successes. Using the number of times admitted to substance abuse treatment as an indicator of successful treatment outcomes, our hypothesis was supported. Women who had a history of sexual trauma were significantly higher on the number of times they had been admitted to substance abuse treatment (trauma $=2.39$, no trauma $=1.48 ; t=3.16, p<.01$ ).

Together, these findings indicate that women with a history of sexual trauma differ from women without such a history in their abuse of substances and treatment experiences but not in their use of substances. Additional analyses were conducted to rule out the possibility that the severity of addiction was related to sexual trauma because women who had been traumatized had been using substances longer. There was no difference between women who had been sexually traumatized and women who had not in the age of first substance use, suggesting that the length of substance use cannot explain the relationship between sexual trauma and severity of addiction.

We also examined whether particular characteristics of the trauma (duration of abuse, age at onset, and relationship to perpetrator) were related to the women's substance use, abuse and treatment histories. The duration of the abuse was positively related to the number of drugs addicted to $(r=.18, p<.05)$ but was not related to drug use, other indicators of severity of addiction, and treatment experiences. There were no significant differences between women who had been sexually traumatized by a family member and women who had not been traumatized by a family member on any of the drug use, abuse, or treatment history variables. Furthermore, the age at onset of sexual trauma was also found to be unrelated to these outcome variables. 


\section{DISCUSSION}

Findings from this study indicate that sexual trauma is related to differences in addiction and treatment experiences in a sample of African American women who smoke crack cocaine. Using both subjective and objective indicators, we found evidence that women who had previously experienced sexual trauma were more severely addicted to substances than women who did not have these experiences. Women with a history of sexual trauma reported being addicted to more substances, being admitted to the hospital and emergency room more often for substance-related issues, and being unable to care for their children more often because of their drug use. We also obtained evidence that women with a history of sexual trauma had greater difficulty breaking their addictions than women without such a history; women who had been sexually traumatized had more previous treatment experiences than women who had not been sexually traumatized.

While our study indicated that women with a history of sexual trauma differ from women without such a history in the severity of their addiction, there were no differences between the groups in the use of substances. Women who had been sexually traumatized reported using the same amount of substances as women who had not been sexually traumatized. It is possible that other factors besides previous traumatic experiences are related to initiation to substance use. For example, previous research indicates that women are initiated into illicit drug use via their interpersonal relationships, such as romantic partner, suggesting that whether or not one's social network includes substance abusing individuals may partly explain substance use in women $(27,28)$.

Our investigation also found some evidence that the severity of the sexual trauma was related to the severity of addiction; specifically, the duration of sexual trauma was positively related to the number of drugs to which the women reported being addicted. However, the age at which sexual abuse began and the relationship to the perpetrator were unrelated to substance use, abuse, and treatment histories. These findings, in conjunction with the ones discussed earlier, suggest that sexual trauma in general has implications for women's substance use; however, trauma that continues to occur over a long period of time can have even more damaging effects on the lives of women. It is important to note, however, that we were limited in our ability to measure a wide range of characteristics pertaining to the women's experiences of sexual trauma. Other factors, such as the degree of violence involved in the trauma and the age discrepancy between the victim and the perpetrator have been found to have differential long-term effects on the lives of women (29) and, thus, may be relevant to understanding women's drug abuse experiences.

Many approaches to substance abuse treatment are currently based on a narrow conceptualization of addictive behavior developed from male experiences of substance abuse and recovery. These treatment models may not be appropriate for women and may even make women's experiences with addiction appear deviant and untreatable. Instead, treatment programs for women substance abusers need to start with a model of female addiction that validates the 
experiences of women (30). Given that previous research indicates that experiences of trauma are common among female substance abusers, treatment programs for women should routinely assess for history of trauma as well as psychiatric symptoms that commonly follow traumatic experiences. Treatment programs that focus on the needs of women also should address building self-esteem through skills training, teach coping strategies to deal with stress, and provide psychiatric therapy when appropriate. However, being sensitive to the needs of women who have been traumatized means that treatment programs need to allow women to decide when they are ready to address issues related to their traumatic experiences. Substance use may be used as a form of coping with the aftermath of traumatic experiences. While clearly substance use is a maladaptive form of coping that needs eventually to be replaced, using substances may enable some women to contain their inner experiences so that they are able to function as well as they do in daily life (31). Moreover, female substance abusers with a history of sexual trauma may be returning to unsafe environments once they leave treatment, which can have implications for the issues that can be addressed in treatment. If these women expect to be traumatized in the future, it will be difficult to develop a sense of safety during treatment. Because the establishment of safety is considered the first step in the treatment of trauma (32), addressing issues related to traumatic experiences may not be feasible at that time.

The present study has several limitations. First, we used a relatively small, convenience sample of African American women; our findings should be interpreted with caution and not generalized beyond the sample. Second, our data are retrospective and women were interviewed only once, factors that make statements regarding causality or temporality difficult. Third, our analyses are based on self-report data, which may limit the validity of our findings. Fourth, many of our measures were not ideal due to the fact that this was a secondary analysis of an existing data set. The variables pertaining to severity of substance abuse and treatment provided only gross measures of these constructs and are limited in psychometric validation. Furthermore, we were able to examine only a narrow range of characteristics pertaining to sexual trauma and we did not have a measure of PTSD symptoms in our data set, which limited our ability to explore why sexual trauma is related to substance use for women. Finally, although this study extends previous research, future studies that use longitudinal, prospective designs are needed in order to establish the order of events and better understand substance use among women who use crack cocaine.

\section{ACKNOWLEDGMENTS}

The National Institute on Drug Abuse supported this research (Grant K20 DA00151; Principal Investigator, C. Boyd). Special thanks go to Stephanie McVey, Flint Odyssey House, Inc., and Evangeline Women's Program for their support. 


\section{REFERENCES}

1. Ratner MS: Sex, drugs, and public policy: Studying and understanding the sex-for-crack phenomenon. In: Ratner MS ed. Crack Pipe as Pimp: An Ethnographic Investigation of sex-for-crack exchanges. New York: Lexington Books; 1993

2. Hatchett D: The impact of AIDS on the black community. Crisis 1990; 97(9):28-30

3. Quinn S: AIDS and the African American woman: The triple burden of race, class, and gender. Health Educ Q 1993; 20(3):305-320

4. Davis RE: Trauma and addiction experiences of African American women. West J Nurs Res 1997; 19(4):442-465

5. Boyd CJ, Hill E, Holmes C, Purnell R: Putting drug use in context: Life-lines of African American women who smoke crack. J Substance Abuse Treat 1998; 15(3):235-249

6. Paone D, Chavkin W, Willets I, Friedmann P, Des Jarlais D: The impact of sexual abuse: Implications for drug treatment. J Women's Health 1992; 1(2):149-153

7. Wallace BC: Crack Cocaine: A Practical Treatment Approach for Chemically Dependent. New York: Brunner/Mazel; 1991

8. Rohsenow DJ, Corbett R, Devine D: Molested as children: The hidden contribution to alcohol and substance abuse. Paper presented at the annual meeting of the American Medical Society of Alcohol and Other Drug Dependence, San Francisco; April 1986

9. Teets JM: Childhood sexual trauma of chemically dependent women. J Psychoact Drugs 1995; 27:231-238

10. Miller BA, Downs WR, Gondoli DM, Keil A: The role of childhood sexual abuse in the development of alcoholism in women. Violence Victims 1987; 2(3):157-172

11. Ladwig GB, Andersen MD: Substance abuse in women: Relationship between chemical dependency of women and past reports of physical and/or sexual abuse. Int J Addict 1989; 24:739-754

12. Braband S, Forsyth CJ, LeBlanc JB: Childhood sexual trauma and substance misuse: A pilot study. Substance Use Misuse 1997; 32(10):1417-1431

13. Mullen PE, Martin JL, Andersen JC, Romans SE, Herbison GP: Childhood sexual abuse and mental health in adult life. Br J Psychiatry 1993; 163:721-732

14. Root MPP: Treatment failures: The role of sexual victimization in women's addictive behavior. Am J Orthopsychiatry 1989; 59(4):542-549

15. Najavits LM, Weiss RD, Shaw SR, Muenz LR: "Seeking safety": Outcome of a new cognitivebehavioral psychotherapy for women with posttraumatic stress disorder and substance dependence. J Traumatic Stress 1998; 11(3):437-456

16. Rohsenow DJ, Corbet R, Devine D: Molested as children: A hidden contribution to substance abuse? J Substance Abuse Treat 1988; 5:13-18

17. Paone D, Chavkin W, Willets I, Friedmann P, Des Jarlais D: The impact of sexual abuse: Implications for drug treatment. J Women's Health 1992; 1:149-153

18. El-Bassel N, Gilbert L, Schilling RF, Ivanoff A, Borne D: Correlates of crack abuse among drug-using incarcerated women: Psychological trauma, social support, and coping behaviors. Am J Drug Alcohol Abuse 1996; 22:41-56

19. Ouimette PC, Ahrens C: Moos RH, Finney JW: Posttraumatic stress disorder in substance abuse patients: Relationship to 1-year posttreatment outcomes. Psych Addict Behav 1997; 11(1):34-47

20. Brown PJ, Stout RL, Mueller T: Post-traumatic stress disorder and substance abuse relapse among women: A pilot study. Psych Addict Behav 1996; 10:124-128

21. Chiavaroli T: Rehabilitation from substance abuse in individuals with a history of sexual abuse. J Substance Abuse Treat 1992; 9:349-354

22. Boyd C: The antecedents of women's crack cocaine abuse: Family substance abuse, sexual abuse, depression, and illicit drug use. J Substance Abuse Treat 1993; 10:433-438

23. Boyd C, Guthrie PJ, Whitmarsh J, Henderson D: African American women who smoke crack: Sexual trauma and the mother-daughter relationship. J Psychoact Drugs 1994; 26:243-247

24. Henderson D, Boyd C, Mieczkowski T: Gender, relationships, and crack cocaine. Res Nurs Health 1994; 7:265-272

25. Hser Y, Anglin MD, McGlothlin, W: Sex differences in addict careers. 1. Initiation of use. Am J Drug Alcohol Abuse 1987; 13:33-57

26. Herman J, Russell D, Trocki K: Long-term effects of incestuous abuse in childhood. Am J Psychiatry 1986; 143:1293-1296

27. Pohl J, Boyd CJ: Female addiction: A conceptual analysis. In: Mieczkowski T, ed. Drugs, Crime, and Social Policy: Research, Issues, and Concerns. Boston: Allyn and Bacon; 1992

28. Herman J: Trauma and Recovery. New York: Basic Books; 1992 